\title{
Biomarkers of angiogenesis in twin gestations and the risk of preeclampsia - review of the current literature
}

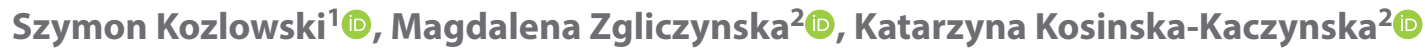 \\ ${ }^{1}$ University Center for Woman and Newborn Health of the Medical University of Warsaw, Poland \\ ${ }^{2}$ Second Department of Obstetrics and Gynecology, Center of Postgraduate Medical Education, Warsaw, Poland
}

\begin{abstract}
Twin pregnancy is one of the key risk factors for the development of preeclampsia.

Soluble fms-like tyrosine kinase-1, placental growth factor, and soluble endoglin are molecules involved in the process of angiogenesis with a proven role in the pathogenesis of preeclampsia. The aim of the review was to summarize available data on maternal serum levels of the biomarkers of angiogenesis and their usefulness in predicting preeclampsia in twin pregnancies. Most of available data suggest biomarkers concentrations differ between singleton and twin gestation and are related to chorionicity of twin pregnancy. Several algorithms including biomarkers of angiogenesis in prediction of PE in twin pregnancy are available and seem promising, however more large prospective surveys are necessary to assess their usefulness in general clinic use.
\end{abstract}

Key words: placental growth factor; serum soluble fms-like tyrosine kinase-1; endoglin; preeclampsia; twin pregnancy

Ginekologia Polska 2020; 91, 12: 773-776

\section{INTRODUCTION}

Pre-eclampsia is one of the most serious pregnancy complications and occurs in approximately $5 \%$ of pregnant women [1]. According to the Polish Society of Gynecologists and Obstetricians, pre-eclampsia (PE) is diagnosed in case of hypertension which develops after 20 gestational weeks accompanied by proteinuria, acute kidney injury, hepatic, hematological or neurological complications, or fetal risks [2]. Currently, two hypotheses are linked to PE etiology: impaired implantation and abnormalities in the immune response of the pregnant woman to the implanted fertilized egg. Abnormal trophoblast implantation and the lack of adequate conversion of the spiral arteries of the uterus lead to trophoblast cell hypoxia and the resultant reperfusion, which is associated with the formation of free radicals and disrupted secretion of angiogenic factors. They include placental growth factor (PIGF), one of the elements of the family of endothelial growth factors (VEGF) which are responsible for angiogenesis. It is secreted in high concentrations by the cyto- and syncytiotrophoblast [3]. Its level increases with the development of gestation reaching the peak around 30 weeks of gestation. Subsequently, the secretion decreases [3]. Soluble fms-like tyrosine kinase-1 (sFlt-1) is a molecule which binds circulating vascular growth factors (PIGF and VEGF) making them biologically inactive.
Intragestationally, sFlt-1 concentration remains constant until approximately 32 weeks, and then it increases [4, 5]. Endoglin (Eng) is a transmembrane glycoprotein which serves as a TGF beta receptor. Its high expression occurs on the surface of decidual cells and the trophoblast [6]. Eng participates in nitrogen oxide metabolism. Therefore, it also influences angiogenesis and vascular function. The concentration of soluble Eng (sEng) correlates with the occurrence of hypertension and proteinuria during pregnancy [7]. Reduced PIGF concentrations and increased sFlt-1 and sEng, which have anti-angiogenic properties, contribute to the development of $\mathrm{PE}$ in singleton pregnancies.

In patients with twin gestations $\mathrm{PE}$ is more common than in single gestations [8]. According to Laine et al. [9], a cohort study conducted in over 16 thousand of twin gestations showed that the risk of PE was over 3-fold higher in twin than single pregnancies. The reason for such a correlation may be linked to the secretion of different amounts of pro- and anti-angiogenic factors by the placenta in single and multiple pregnancies and the difference between placental weight. Published literature includes reports on the correlation between PE occurrence and the type of chorionicity of a twin gestation. However, published data are contradictory. Most studies demonstrated that PE was more common in patients with dichorionic rather than monochorionic gestations 
[10-12]. However, other authors reported a higher frequency of PE in women with a monochorionic pregnancy [13] or the lack of correlation with chorionicity [14-16]. Moreover, the etiology of the above-mentioned correlations is unknown. It may be due to the differences in the secretion of pro- and anti-angiogenic factors by the placenta in mono- and dichorionic gestations. The present paper includes a review of available literature concerning PIGF, sFIt-1 and sEng secretion in mono- and dichorionic twin gestations.

\section{DIFFERENCES IN THE SECRETION OF ANGIOGENIC FACTORS IN SINGLE AND TWIN GESTATIONS}

Placental weight is markedly different between single and twin gestations. According to Bdolah et al. [17] the average weight of the placenta is $716 \mathrm{~g}$ in a single gestation, while in a twin gestation it is considerably larger and weighs on average $1246 \mathrm{~g}(\mathrm{p}<0.001)$. The biomarkers of angiogenesis are released by trophoblast cells, so it may be assumed that their concentration in the sera of patients with single and twin pregnancies are different. The majority of studies published worldwide showed that those hypothetical differences are present. Faupel-Badger et al. [18] investigated the concentration of sFlt- 1 in the sera of patients with single and twin pregnancies at $10,18,26$, and 35 weeks of gestation and perinatally. They demonstrated that sFlt-1 concentrations were higher in twin pregnancies compared to single pregnancies in each of the analyzed time intervals. Similar results were also published by other authors [17-24]. Observations regarding PIGF secretion in single and twin gestations are also consistent. Numerous authors reported higher PIGF concentrations in women with twin gestations compared to single gestations [19-26]. Faupel-Badger et al. [18] observed higher PIGF concentrations in twin gestations than in single gestations in each analyzed interval of gestations except week 35 in which the correlation was inverse. Sanchez et al. analyzed the levels of biomarkers of angiogenesis in single and multiple gestations over the 1st trimester. They reported higher sFlt-1 and PIGF concentrations in twin pregnancies [20]. Maynard et al. [24] analyzed a group of patients with a high risk of PE development between 22 and 36 gestational weeks. In the study group sFlt-1 concentrations were higher and increased more rapidly in twin gestations than in single gestations, while PIGF concentrations were higher than in single gestations, but they decreased more rapidly. Studies concerning sEng presented contradictory results. Three studies have been published so far. They compared sEng concentrations in the sera of patients with single and twin pregnancies. According to Jeyabalan et al. and Faupel-Badger et al. sEng was secreted in higher amounts in patients with twin pregnancies, while Sánchez et al. did not observe such differences [18-20].

\section{DIFFERENCES IN THE SECRETION OF ANGIOGENIC FACTORS IN MONO- AN DICHORIONIC TWIN GESTATIONS}

No unambiguous data have been published in professional literature available worldwide to confirm whether PIGF, sFlt-1 and sEng secretion was dependent on the chorionicity in twin gestations. Cowans and Spencer [27] analyzed PIGF concentrations in 440 dichorionic, 116 monochorionic and in 607 single pregnancies in the $1^{\text {st }}$ trimester. Higher PIGF concentrations were noted in $41 \%$ of dichorionic gestations and in $16 \%$ of monochorionic gestations compared to single gestations. Francisco et al. [26] also reported a higher PIGF concentration in the serum of women with dichorionic twin gestations compared to monochorionic and single gestations in the $1^{\text {st }}$ trimester. Faupel-Badger et al. [18] determined sFlt-1 and sEng concentrations in subsequent measurements during pregnancy. The authors noted higher sFlt- 1 and sEng concentrations in monochorionic compared to dichorionic gestations, also after correlations were made according to gestational age. Conversely, contradictory results have also been published in professional literature worldwide. Sanchez et al. [20] and Svirsky et al. [25] reported no differences in the secretion of PIGF, sFlt-1 and sEng between mono- an dichorionic gestations.

\section{DIFFERENCES IN THE SECRETION OF ANGIOGENIC FACTORS IN TWIN GESTATIONS COMPLICATED AND UNCOMPLICATED WITH PE}

In 2016 Tsiakkas et al. [28] reported on the distribution of PIGF concentrations at weeks 12, 22, 32 and 36 of single gestations complicated and uncomplicated with PE. Having examined over 40 thousand pregnant women the authors concluded that lower PIGF concentrations were strongly correlated with PE development. In the same year, the results of PROGNOSIS study were published. It was a prospective observational cohort study conducted in over 1000 women whose sFlt-1:PIGF ratio was determined between 24 and 36 weeks of gestation in order to assess its usefulness in the prediction of PE occurrence. The study showed a high negative predictive value of sFlt-1:PIGF ratio $<38$ for PE development over the following 7 days (99.3\%) and a $66 \%$ sensitivity for the ratio $>38$ for the development of PE over the following four weeks [29]. Those findings facilitated the development of sensitive methods of PE prediction in single pregnancies.

However, professional literature available worldwide includes no such explicit results as regards the correlation of the biomarkers of angiogenesis with the risk of PE in twin gestations. Most published reports showed that sFlt-1 concentrations in twin gestations complicated by PE were higher than in gestations uncomplicated by PE [19-22, 30]. Moreover, lower PIGF concentrations were observed in 
gestations with PE $[19,21,22,25,26,31,32]$. The differences between both biomarkers were confirmed in all trimesters of gestation. According to Dröge et al. an increased sFlt-1:PIGF ratio is associated with a higher risk of $\mathrm{PE}$ in twin gestations. The authors reported higher sFlt-1 and lower PIGF concentrations in twin pregnancies with PE. sFIt-1:PIGF ratio was as high in twin gestations with $\mathrm{PE}$ as in single gestations complicated by PE [22]. Independent teams of Powers et al. and Metz et al. demonstrated an analogous correlation between sFlt-1+sEng:PIGF index and the development of $P E$ in twin gestations [19, 31]. Jeyabalan et al. [19] also noted significantly higher sEng concentrations between 31 and 35 gestational weeks in women who developed PE. Dröge et al. also analyzed the correlation between PE severity and the concentrations of angiogenesis biomarkers in twin gestations. The authors observed a significantly higher sFIt-1 and lower PIGF concentration both in mild and severe pre-eclampsia compared to uncomplicated gestations [22].

The analysis of professional literature also showed contradictory results which revealed no differences between the concentrations of angiogenesis biomarkers in twin gestations complicated and uncomplicated with PE. According to Sanchez et al. [20] sFlt-1 concentrations were similar in the sera of women with PE and uncomplicated ones. Furthermore, Saleh et al. [23] noted no significant differences regarding PIGF and sFlt-1 secretion in pregnancies complicated and uncomplicated by PE. However, their study included only 21 women.

Basing on the observed differences, a number of authors assessed the usefulness of those biomarkers in the models of PE prediction in twin gestations. Rana et al. [33] developed an algorithm to estimate the risk of PE-related complications in twin gestations for the following 2 weeks. The algorithm is based on gestational age, the highest measurement of blood pressure, the presence of proteinuria and the value of sFlt-1:PIGF ratio. The area under the curve (AUC) reached 0.93 with the use of all the above elements. In $86 \%$ of women whose sFIt-1:PIGF ratio reached or exceeded 85 , the delivery occurred within two weeks following the measurement. However, various authors disagreed as regards the cut-off value of sFIt-1:PIGF ratio for twin gestations. According to Dröge et al. [22] the optimal cut-off value for PE prediction in twin gestations was $\geq 53$. Saleh et al. [23] verified the usefulness of $\leq 38$ ratio to rule out short-term risk of $P E$ development in twin gestations. However, 5 out of 13 women with the ratio of $>38$ and 4 out of 8 women with the ratio of $\leq 38$ developed PE. The authors concluded that the value of the ratio of $\leq 38$ was not useful in twin gestations. Predictive algorithms of the $1 \mathrm{st}$ trimester of pregnancy seem to be more effective. Boucoiran et al. [21] demonstrated a high effectiveness of PE prediction in the 1st trimester of a twin gestation with the use of PIGF concentrations (AUC 0.81, $10 \%$ of false positive results). Francisco et al. developed a PE predictive model comprising maternal factors, mean blood pressure, the pulsatility index of uterine arteries and PIGF concentration in the $1^{\text {st }}$ trimester of pregnancy. The detection rate of PE resulting in delivery prior to 32 weeks of gestation was $100 \%$ (AUC 0.94), while before 37 weeks of gestation it was $99 \%$ (AUC 0.82). However, the percentage of false positive results was high (75\%) [26]. The algorithm is available online: https://fetalmedicine.org.

The presented options of algorithms to predict PE seem promising. However, it is still impossible to assess their clinical usefulness. It is necessary to conduct a large prospective study and include such factors as twin gestation chorionicity or PE severity. The inclusion of such factors is necessary to improve the algorithms before they are recommended for general use. The development of an effective algorithm would contribute to the improvement of the perinatal care of women with twin gestations and the improvement of the perinatal results of twin gestations.

\section{SUMMARY}

Twin pregnancy is one of the risk factors for development of PE. Soluble fms-like tyrosine kinase-1, placental growth factor, and soluble endoglin are biomarkers involved in the process of angiogenesis with a proven role in the pathogenesis of PE. Most of available data suggest their concentrations differ between singleton and twin gestation and between monochorionic and dichorionic twin pregnancy. Several algorithms including biomarkers of angiogenesis in prediction of PE in twin pregnancy are available and seem promising, however more large prospective surveys are necessary to assess their usefulness in general clinic use.

\section{REFERENCES}

1. Abalos E, Cuesta C, Grosso AL, et al. Global and regional estimates of preeclampsia and eclampsia: a systematic review. Eur J Obstet Gynecol Reprod Biol. 2013; 170(1): 1-7, doi: 10.1016/j.ejogrb.2013.05.005, indexed in Pubmed: 23746796.

2. Prejbisz A, Dobrowolski P, Kosiński P, et al. Postępowanie w nadciśnieniu tętniczym u kobiet w ciąży. Zapobieganie, diagnostyka, leczenie i odległe rokowanie. Stanowisko Polskiego Towarzystwa Nadciśnienia Tętniczego, Polskiego Towarzystwa Kardiologicznego oraz Polskiego Towarzystwa Ginekologów i Położników. Ginekologia i Perinatologia Praktyczna. 2019; 4(2): 43-111.

3. Williams D, Kenyon A, Adamson D. Physiology. In: Bennett P, Williamson C. ed. Basic Science in Obstetrics and Gynaecology, 4th ed. Churchill Livingstone, London 2010: 173-230.

4. Phipps EA, Thadhani R, Benzing T, et al. Pre-eclampsia: pathogenesis, novel diagnostics and therapies. Nat Rev Nephrol. 2019; 15(5): 275-289, doi: 10.1038/s41581-019-0119-6, indexed in Pubmed: 30792480.

5. Birdir C, Droste L, Fox L, et al. Predictive value of sFlt-1, PIGF, sFIt-1/PIGF ratio and PAPP-A for late-onset preeclampsia and IUGR between 32 and 37 weeks of pregnancy. Pregnancy Hypertens. 2018; 12: 124-128, doi: 10.1016/j.preghy.2018.04.010, indexed in Pubmed: 29674192.

6. Venkatesha S, Toporsian M, Lam C, et al. Soluble endoglin contributes to the pathogenesis of preeclampsia. Nat Med. 2006; 12(6): 642-649, doi: 10.1038/nm1429, indexed in Pubmed: 16751767.

7. Leaños-Miranda A, Navarro-Romero CS, Sillas-Pardo LJ, et al. Soluble Endoglin As a Marker for Preeclampsia, Its Severity, and the Occurrence of Adverse Outcomes. Hypertension. 2019; 74(4): 991-997, doi: 10.1161/HYPERTENSIONAHA.119.13348, indexed in Pubmed: 31446801. 
8. ACOG Practice Bulletin No. 202 Summary: Gestational Hypertension and Preeclampsia. Obstet Gynecol. 2019; 133(1): 211-214, doi: 10.1097/AOG.0000000000003019, indexed in Pubmed: 30575668.

9. Laine K, Murzakanova G, Sole KB, et al. Prevalence and risk of pre-eclampsia and gestational hypertension in twin pregnancies: a population-based register study. BMJ Open. 2019; 9(7): e029908, doi: 10.1136/bmjopen-2019-029908, indexed in Pubmed: 31278106.

10. Bartnik P, Kosinska-Kaczynska K, Kacperczyk J, et al. Twin Chorionicity and the Risk of Hypertensive Disorders: Gestational Hypertension and Pre-eclampsia. Twin Res Hum Genet. 2016; 19(4): 377-382, doi: 10.1017/thg.2016.17, indexed in Pubmed: 27160962.

11. Sarno L, Maruotti GM, Donadono V, et al. Risk of preeclampsia: comparison between dichorionic and monochorionic twin pregnancies. J Matern Fetal Neonatal Med. 2014; 27(10): 1080-1081, doi: 10.3109/14767058.2013.847414, indexed in Pubmed: 24060182.

12. Sparks TN, Cheng YW, Phan N, et al. Does risk of preeclampsia differ by twin chorionicity? J Matern Fetal Neonatal Med. 2013; 26(13): 1273-1277, doi: 10.3109/14767058.2013.777701, indexed in Pubmed: 23425367.

13. Campbell DM, Templeton A. Maternal complications of twin pregnancy. Int J Gynaecol Obstet. 2004; 84(1): 71-73, doi: 10.1016/s0020-7292(03)00314-x, indexed in Pubmed: 14698833.

14. Campbell DM, MacGillivray I. Preeclampsia in twin pregnancies: incidence and outcome. Hypertens Pregnancy. 1999; 18(3): 197-207, doi: 10.3109/10641959909016193, indexed in Pubmed: 10586523.

15. Savvidou MD, Karanastasi E, Skentou C, et al. Twin chorionicity and pre-eclampsia. Ultrasound Obstet Gynecol. 2001; 18(3): 228-231, doi: 10.1046/j.0960-7692.2001.00470.x, indexed in Pubmed: 11555451.

16. Leduc L, Takser L, Rinfret D. Persistance of adverse obstetric and neonatal outcomes in monochorionic twins after exclusion of disorders unique to monochorionic placentation. Am J Obstet Gynecol. 2005; 193(5): 16701675, doi: 10.1016/j.ajog.2005.04.007, indexed in Pubmed: 16260208.

17. Bdolah Y, Lam C, Rajakumar A, et al. Twin pregnancy and the risk of preeclampsia: bigger placenta or relative ischemia? Am J Obstet Gynecol. 2008; 198(4): 428.e1-428.e6, doi: 10.1016/j.ajog.2007.10.783, indexed in Pubmed: 18191808.

18. Faupel-Badger JM, McElrath TF, Lauria $M$, et al. Maternal circulating angiogenic factors in twin and singleton pregnancies. Am J Obstet Gynecol. 2015; 212(5): 636.e1-636.e8, doi: 10.1016/j.ajog.2014.11.035, indexed in Pubmed: 25434840.

19. Jeyabalan A, Powers RW, Clifton RG, et al. Eunice Kennedy Shriver National Institute of Child Health and Human Development Maternal-Fetal Medicine Units Network, Eunice Kennedy Shriver National Institute of Child Health Human Development Maternal-Fetal Medicine Units Network. Soluble fms-Like tyrosine kinase 1 (sFlt1), endoglin and placental growth factor (PIGF) in preeclampsia among high risk pregnancies. PLoS One. 2010; 5(10): e13263, doi: 10.1371/journal.pone.0013263, indexed in Pubmed: 20948996.

20. Sánchez O, Llurba E, Marsal G, et al. First trimester serum angiogenic/anti-angiogenic status in twin pregnancies: relationship with assisted reproduction technology. Hum Reprod. 2012; 27(2): 358-365, doi: 10.1093/humrep/der394, indexed in Pubmed: 22116949.

21. Boucoiran I, Thissier-Levy S, Wu Y, et al. MIROS Study Group. Risks for preeclampsia and small for gestational age: predictive values of placental growth factor, soluble fms-like tyrosine kinase-1, and inhibin A in singleton and multiple-gestation pregnancies. Am J Perinatol. 2013; 30(7): 607-612, doi: 10.1055/s-0032-1329691, indexed in Pubmed: 23208763.

22. Dröge $L$, Herraìz I, Zeisler $\mathrm{H}$, et al. Maternal serum sFIt-1/PIGF ratio in twin pregnancies with and without pre-eclampsia in comparison with singleton pregnancies. Ultrasound Obstet Gynecol. 2015; 45(3): 286-293, doi: 10.1002/uog.14760, indexed in Pubmed: 25491901

23. Saleh L, Tahitu SIM, Danser AH, et al. The predictive value of the sFlt$1 /$ PIGF ratio on short-term absence of preeclampsia and maternal and fetal or neonatal complications in twin pregnancies. Pregnancy Hypertens. 2018; 14: 222-227, doi: 10.1016/j.preghy.2018.03.014, indexed in Pubmed: 29678353.

24. Maynard SE, Moore Simas TA, Solitro MJ, et al. Circulating angiogenic factors in singleton vs multiple-gestation pregnancies. Am J Obstet Gynecol. 2008; 198(2): 200.e1-200.e7, doi: 10.1016/j.ajog.2007.08.042, indexed in Pubmed: 18226624.

25. Svirsky R, Levinsohn-Tavor O, Feldman N, et al. First- and second-trimester maternal serum markers of pre-eclampsia in twin pregnancy. Ultrasound Obstet Gynecol. 2016; 47(5): 560-564, doi: 10.1002/uog.14873, indexed in Pubmed: 25865365.

26. Francisco $C$, Wright $D$, Benkő $Z$, et al. Competing-risks model in screening for pre-eclampsia in twin pregnancy according to maternal factors and biomarkers at 11-13 weeks' gestation. Ultrasound Obstet Gynecol. 2017; 50(5): 589-595, doi: 10.1002/uog.17531, indexed in Pubmed: 28556556.

27. Cowans NJ, Spencer K. First trimester maternal serum placental growth factor levels in twin pregnancies. Prenat Diagn. 2013; 33(13): 1260-1263, doi: 10.1002/pd.4243, indexed in Pubmed: 24114956.

28. Tsiakkas A, Cazacu R, Wright A, et al. Maternal serum placental growth factor at 12, 22, 32 and 36 weeks' gestation in screening for pre-eclampsia. Ultrasound Obstet Gynecol. 2016; 47(4): 472-477, doi: 10.1002/uog.15816, indexed in Pubmed: 26582455.

29. Zeisler H, Llurba E, Chantraine F, et al. Predictive Value of the sFlt-1:PIGF Ratio in Women with Suspected Preeclampsia. N Engl J Med. 2016 374(1): 13-22, doi: 10.1056/NEJMoa1414838, indexed in Pubmed: 26735990.

30. Rana S, Hacker MR, Modest AM, et al. Circulating angiogenic factors and risk of adverse maternal and perinatal outcomes in twin pregnancies with suspected preeclampsia. Hypertension. 2012; 60(2): 451-458, doi: 10.1161/HYPERTENSIONAHA.112.195065, indexed in Pubmed: 22753210.

31. MetzTD, Allshouse AA, Euser AG, et al. Preeclampsia in high risk women is characterized by risk group-specific abnormalities in serum biomarkers. Am J Obstet Gynecol. 2014; 211(5): 512.e1-512.e6, doi: 10.1016/j. ajog.2014.04.027, indexed in Pubmed: 24769011.

32. Maymon R, Trahtenherts A, Svirsky R, et al. Developing a new algorithm for first and second trimester preeclampsia screening in twin pregnancies. Hypertens Pregnancy. 2017; 36(1): 108-115, doi: 10.1080/10641955.2016.1242605, indexed in Pubmed: 27835040.

33. Rana S, Powe CE, Salahuddin S, et al. Angiogenic factors and the risk of adverse outcomes in women with suspected preeclampsia. Circulation. 2012; 125(7): 911-919, doi: 10.1161/CIRCULATIONAHA.111.054361, indexed in Pubmed: 22261192. 